\title{
Relationship between Human Papilloma Virus and Subungual Keratoacanthoma: Two Case Reports and the Outcomes of Surgical Treatment
}

\author{
Fatih Göktay $^{\mathrm{a}}$ Emre Kaynak ${ }^{\mathrm{a}}$ Pembegül Güneş ${ }^{\mathrm{b}}$ Şirin Yaşar ${ }^{\mathrm{a}}$

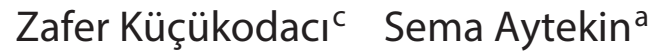 \\ Departments of ${ }^{a}$ Dermatology and ${ }^{b}$ Pathology, University of Health Sciences, Haydarpaşa Numune Training and \\ Research Hospital, and ' Department of Medical Pathology, Gülhane Military Medical Academy, İstanbul, Turkey
}

\section{Established Facts}

- Trauma and human papilloma virus infection (HPV) have been suggested as etiological factors of keratoacanthoma lesions.

\section{Novel Insights}

- Unlike other clinical forms, the relationship between HPV and subungual keratoacanthoma (SUKA) has not been studied.

- HPV type 6 may be detected in SUKA lesions, but it does not seem to cause any significant histopathological findings, and the etiological role of an HPV infection remains elusive with regard to SUKA lesions.

- Because the tumor cells were not detected in the curettage material underlying damaged bone, simple excision (with or without curettage) seemed to be sufficient for the treatment of SUKA lesion.

\section{Key Words}

Nail tumor - Keratoacanthoma · Human papilloma virus . Bone $\cdot$ Curettage $\cdot$ Liquid-based thin-layer slide $\cdot$ Cell block

\footnotetext{
Abstract

Subungual keratoacanthoma (SUKA) is a rare form of keratoacanthoma, with the majority of the lesions appearing as rapidly growing, painful hyperkeratotic masses located under the distal nail plate of the thumb. In some cases, SUKA causes damage to the underlying bone. The first case presented here was treated by surgical excision alone, and hu-
}

man papilloma virus (HPV) type 6 was detected in the tissue samples. The second case was treated by surgical excision plus curettage; however, HPV was not detected, and tumor cells were not found in the curettage material. There was near complete improvement in both the clinical appearance and the distal phalanx destruction, with no recurrence at the final follow-up in either patient (30 and 14 months, respectively). Overall, simple excision alone or in combination with curettage seemed to be sufficient in the treatment of SUKA; however, the etiopathogenetic role of HPV in SUKA remains controversial, as in its classical form.

(c) 2016 S. Karger AG, Basel

\section{KARGER}

E-Mail karger@karger.com www.karger.com/sad
(C) 2016 S. Karger AG, Basel

2296-9195/16/0024-0092\$39.50/0
Fatih Göktay, MD

Haydarpaşa Numune Eğitim ve Araştırma Hastanesi Dermatoloji Kliniği Tibbiye cad.

TR-34668 Üsküdar/İstanbul (Turkey)

E-Mail fatihgoktay@yahoo.com 


\section{Introduction}

Subungual keratoacanthoma (SUKA) is a rare destructive form of keratoacanthoma, which may be solitary, multiple, eruptive, and sometimes familial, and usually occurs in middle-aged men [1]. The majority of the lesions appear as painful hyperkeratotic masses located under the distal nail plate of the thumb; characteristically, SUKA exhibits rapid growth and can cause damage to the underlying bone [2]. Although both trauma and human papilloma virus (HPV) infections have been suggested as etiological factors of this disease, these associations have not been fully clarified $[2,3]$. Here, we present two cases of SUKA, along with their clinical, histopathological, and HPV findings, as well as the surgical treatment outcomes of the patients.

\section{Case Reports}

\section{Case 1}

A 62-year-old male patient presented with a 2-month history of a painful subungual mass on the second finger of his left hand. Dermatological examination revealed subungual hyperkeratotic papules pushing the nail plate (slightly) up, yellowish discoloration of the nail plate, and distal onycholysis (fig. 1a). An X-ray of the involved digit showed minimal osteolysis on the distal phalanx, just beneath the subungual mass (fig. 1b); consequently, an excision was performed (fig. 1c-f). The histopathological examination was compatible with a diagnosis of keratoacanthoma (fig. 2a, b), and type $6 \mathrm{HPV}$ was detected in the paraffin-embedded tissue sample via polymerase chain reaction (PCR) (fig. 3). After treatment, there was no recurrence, and the distal minimal bone destruction had resolved at the end of the 12-month follow-up (fig. 1h). The nail plate was completely normal at the 30 -month follow-up (fig. 1g).

\section{Case 2}

A 71-year-old male patient was referred to our clinic with a 6-month history of a painful (to the touch) mass under the fourth fingernail of his left hand. During the dermatological examination, a slightly erythematous nodule was detected with a central hyperkeratotic plug protruding from the hyponychium and pushing the distal nail plate up. Upon X-ray examination, prominent osteolysis was seen on the tip of the distal phalanx, just beneath the lesion. The lesion was excised, in total, and the exposed bone and soft tissue were curetted using a Volkmann curette. The excised and curetted tissues were sent separately to the pathology department, and the histopathological findings were consistent with keratoacanthoma. However, tumor cells were not detected in the microscopic examination of the liquid-based thin-layer slide or the cell block prepared from the tissue obtained by curettage. Via real-time PCR, HPV DNA could not be detected in the paraffin-embedded tumoral tissue sample of this patient (fig. 3a). The lesion did not reoccur, and nearly complete ossification of the distal phalanx was observed at the end of the 14-month follow-up.
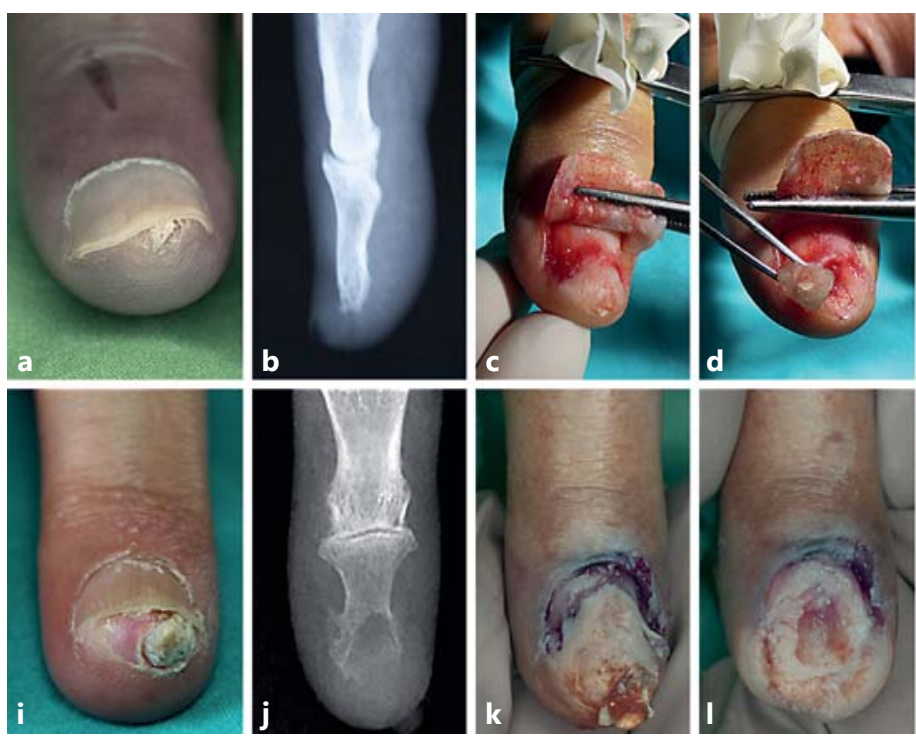

Fig. 1. a-h Case 1. a Clinical image of the patient. b Preoperative $\mathrm{X}$-ray image showing minimal distal osteolysis. c-f Surgical excision of the lesion. $\mathbf{g}$ Postoperative clinical image of the patient at the end of the 30-month follow-up. $\mathbf{h}$ Reossification of the tip of the distal phalanx. i-p Case 2. i Clinical image of the patient. $\mathbf{j}$ X-
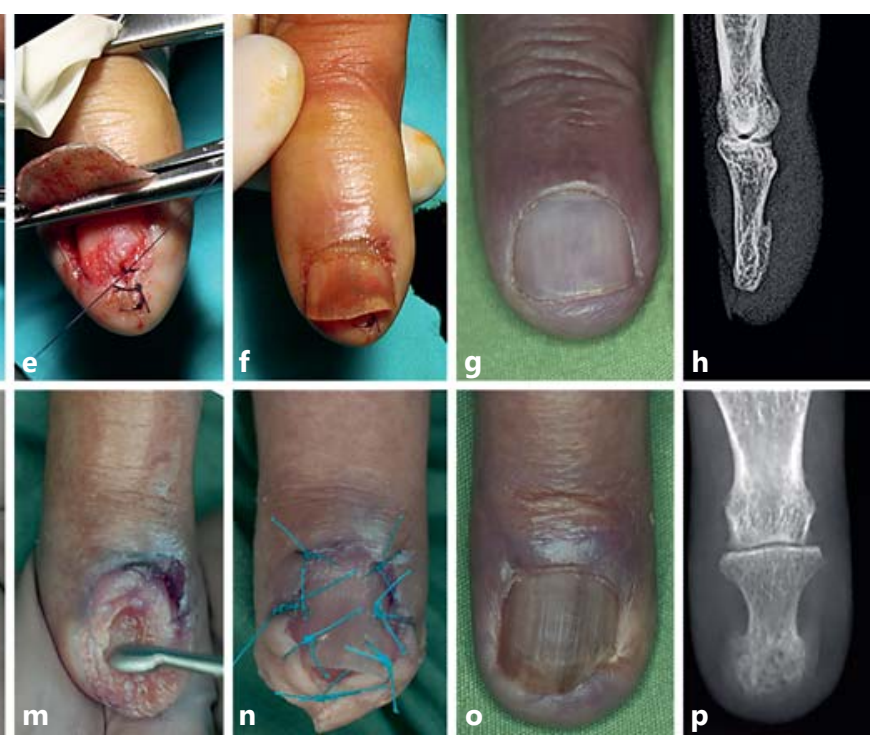

ray image showing bowl-like bone destruction on the dorsal aspect of the tip of the distal phalanx. k-n Images of the surgical excision and curettage. $o$ Postoperative clinical image of the patient at the end of the 14-month follow-up. p Near complete reossification of the distal phalanx. 

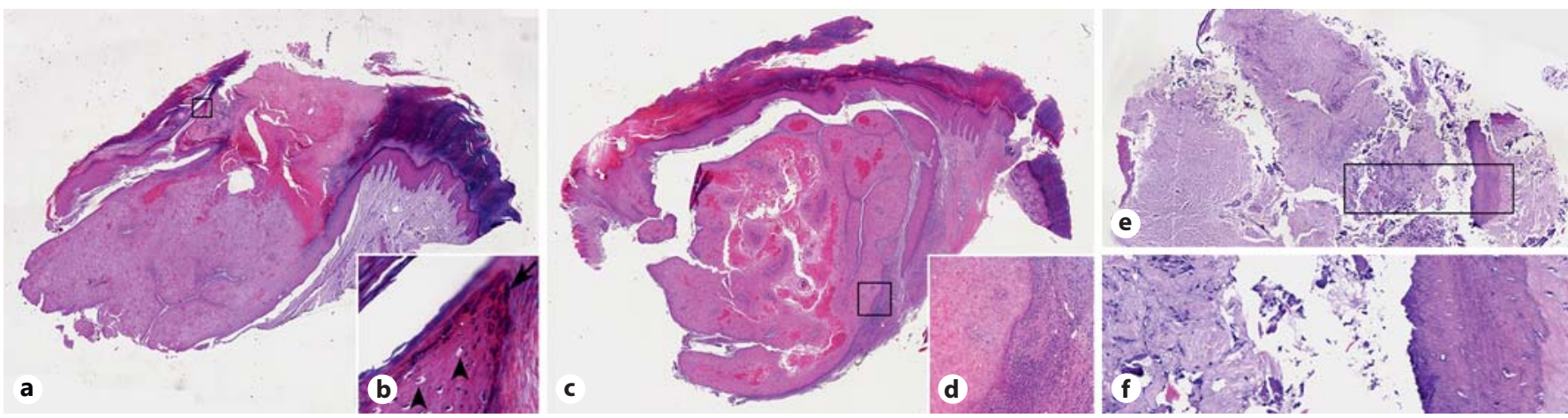

Fig. 2. a, b Case 1. a Neoplastic squamous epithelial proliferation in an endophytic pattern extending into the dermis, parakeratosis, and marked hypergranulosis in the papillomatous projections in the crater. H\&E. $\times 40$. b Beneath the hypergranular layer (arrow), a few keratinocytes can be seen with perinuclear halos, but without nuclear hyperchromasia and membrane irregularities (arrowheads). H\&E. $\times 200$. c-f Case 2. c Compact hyperkeratosis and squamous epithelial proliferation in a crateriform endophytic pattern extending into the dermis. Proliferating keratinocytes showing enlarged eosinophilic cytoplasm, mild nuclear atypia, a frosted glass appearance, and single-cell necrosis. Epithelial proliferation

\section{Discussion}

Although it is still controversial, the relationship between an HPV infection and keratoacanthoma has previously been investigated. For example, in the study of Forslund et al. [3], 72 fresh excisional biopsy specimens of keratoacanthoma lesions from 32 patients $(21 \mathrm{immu}-$ nosuppressed, 11 non-immunosuppressed) were analyzed by PCR to search for HPV DNA. HPV DNA was found to be positive in 55\% (33/60) of keratoacanthoma lesions of immunosuppressed patients, and in 33\% (4/12) of those of non-immunosuppressed patients. Various studies have demonstrated genital HPV (including type 6) harbored in keratoacanthoma lesions $[4,5]$. As far as we know, our study is the first to investigate the presence of HPV DNA in keratoacanthomas arising from the nail bed, which is a special and unexpected anatomical region for keratoacanthoma lesions. We detected type $6 \mathrm{HPV}$ DNA in only one of our patients (case 1). Unlike case 2, the histopathological examination of case 1 revealed a few keratinocytes, beneath the hypergranular layer, with perinuclear halos, without nuclear hyperchromasia or membrane irregularities, which may have been associated with the viral cytopathic effect. However, these confounding changes that mimic HPV infections can also be seen in acral biopsies, such as in acral fibrokeratomas [6]. In the showing papillary projections toward the surface of the tumor, but no parakeratosis or hypergranulosis is seen in these structures. In the endophytic squamous epithelial islands, there were more anucleic squamous and dyskeratotic cells when compared to the first case. There was severe inflammatory cell infiltration in the papillary dermis. H\&E. $\times 40$. d Many eosinophils, leukocytes, lymphocytes, and histiocytes at the base of the tumor. H\&E. $\times 200$. e Microscopic examination of the curettage material revealed stromal tissue fragments, dissociated bone fragments, and spindle cells, but there were no atypical cells or tumors in this preparation. H\&E. $\times 100$. f Close-up of image e. H\&E. $\times 200$. second case, there were more anucleated squamous and dyskeratotic cells, with plenty of eosinophils, leukocytes, lymphocytes, and histiocytes at the base of the lesion (compared to the first case). Whether or not these differences are related to an HPV infection requires clarification.

Bone erosion of the distal phalanx is commonly detected in the X-ray examination of patients with SUKA, and it has been suggested that this erosion is the result of pressure from the tumor. Osteolysis of the distal phalanx can also be caused by squamous cell carcinoma, an intraosseous ganglion, a glomus tumor, or an epidermal cyst [7]. In addition to its help in the diagnosis of SUKA, during the posttreatment clinical course, bone erosion may be used as a follow-up parameter, indirectly indicating healing or recurrence [2]. Bone erosion was detected in both of our cases in correlation with the severity of the disease, which rapidly and completely disappeared in the first, mild case. In the second case, which was relatively more severe, substantial improvement in the bone erosion was detected via X-ray examination at the end of the 14-month follow-up.

In the differential diagnosis of SUKA, the following should be considered: dermoid cyst, subungual fibroma, glomus tumor, giant cell tumor of the tendon sheath, digital mucoid cyst, common wart, subungual exostosis, 

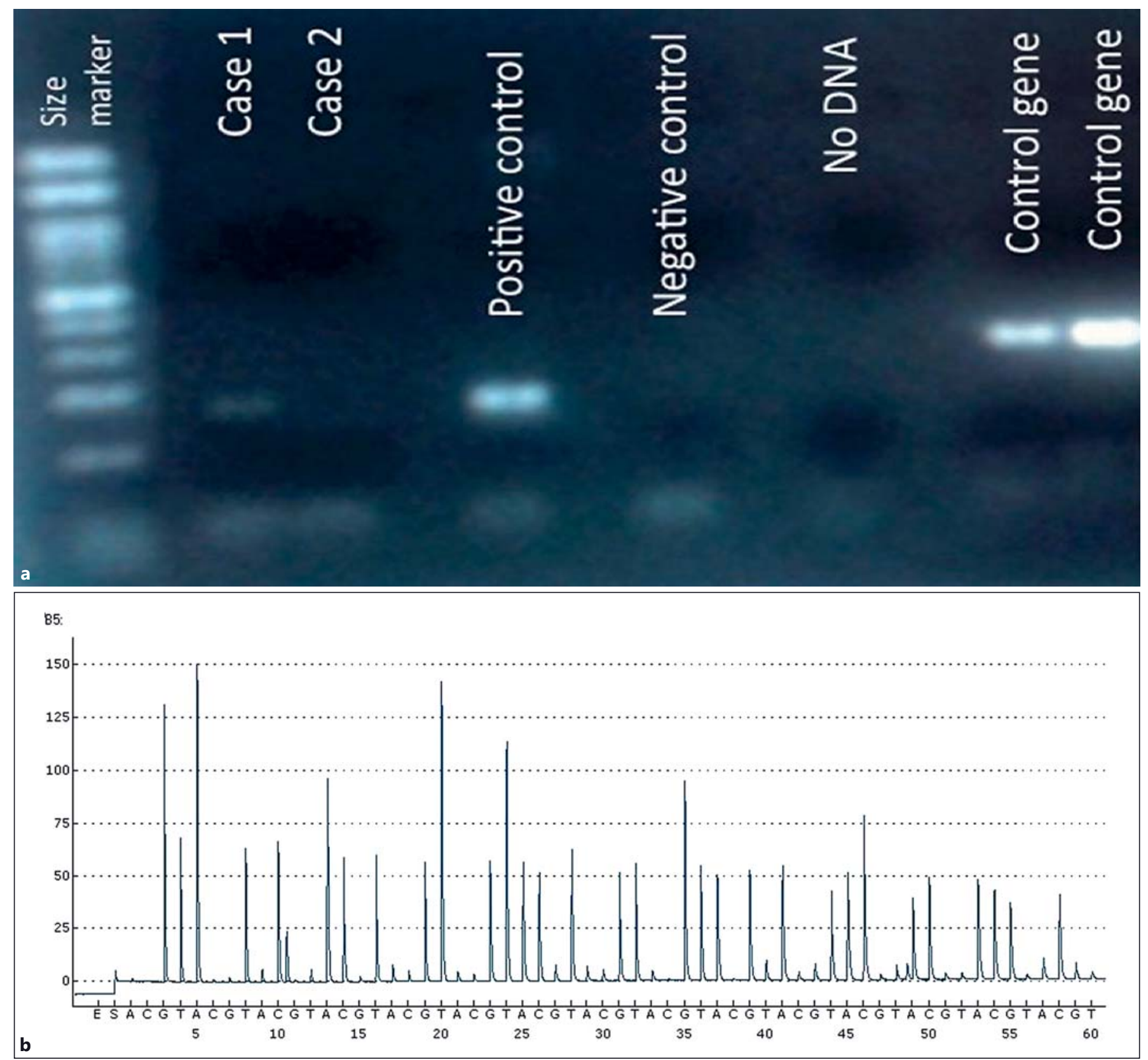

Fig. 3. a Agarose gel image. b Detailed identifier report and pyrogram image of case 1.

amelanotic melanoma, and subungual squamous cell carcinoma [8]. SUKA was not considered in the prediagnosis of our first case, which may have been because of its indistinctive clinical appearance; however, based on the experience gained from the first case and the prominent clinical features, SUKA was the first prediagnosis of our second case. SUKA has an aggressive clinical course, and may spontaneously resolve; still, this is rare, and the literature does not support an accepted safe period of observation for SUKA [9]. Initially, local excision and curettage are sufficient for treatment, but amputation may be necessary either because of the aggressive nature of the disease, or extensive osteolysis or recurrence after excision and curettage $[1,2,10]$. There is no certain recur- 
rence ratio, but most of the recurrences occurred within the first 5 months [2].

Because of the absence of a prediagnosis of keratoacanthoma, as a diagnostic and therapeutic approach, simple excision without curettage was performed in our first case. Our second case, which was prediagnosed as keratoacanthoma, was diagnosed and treated by excision plus curettage. However, histopathologically, tumor cells could not be detected in the curettage material. In both of our cases, the cosmetic results were quite satisfactory, and no recurrence was detected at the end of the considerably long follow-up periods.

In conclusion, as seen in our patients, lesion duration, presence of pain, hyperkeratotic plug, and bone destruction may provide clues for the clinical prediagnosis of SUKA. For the early diagnosis and treatment of distal subungual lesions presenting with similar clinical features, dermatologists should not refrain from preferentially performing excisional biopsies after the initial radiographic evaluation. According to our results, simple excision (with or without curettage) seemed to be sufficient for the treatment of SUKA. After treatment, along with the clinical examination, checking the bone erosion changes via X-ray may be an objective follow-up method for evaluating the clinical course and recurrence of the disease. Overall, HPV DNA harbored in SUKA lesions does not cause any significant histopathological findings, and the etiological role of an HPV infection remains elusive with regard to SUKA lesions.

\section{Statement of Ethics}

This study is a retrospective case series study. The cases are presented with their nonidentifiable images. Ethical committee approval could be waived.

\section{Disclosure Statement}

The authors declare no conflicts of interest.

\section{References}

1 Baran R, Goettmann S: Distal digital keratoacanthoma: a report of 12 cases and a review of the literature. Br J Dermatol 1998;139:512515.

2 Baran R, Mikhail G, Costini B, Tosti A, Goettmann-Bonvallot S: Distal digital keratoacanthoma: two cases with a review of the literature. Dermatol Surg 2001;27:575-579.

3 Forslund O, DeAngelis PM, Beigi M, Schjolberg AR, Clausen OP: Identification of human papillomavirus in keratoacanthomas. J Cutan Pathol 2003;30:423-429.

4 Stockfleth E, Meinke B, Arndt R, Christophers E, Meyer T: Identification of DNA sequences of both genital and cutaneous HPV types in a small number of keratoacanthomas of nonimmunosuppressed patients. Dermatology 1999;198:122-125.
5 Saftic M, Batinac T, Zamolo G, Coklo M, Simat M, Mustac E, Bosnar A, Grahovac B: HPV 6-positive giant keratoacanthoma in an immunocompetent patient. Tumori 2006;92: 79-82.

6 Goktay F, Altan ZM, Haras ZB, Gunes P, Yasar S, Aytekin S, Haneke E: Multibranched acquired periungual fibrokeratomas with confounding histopathologic findings resembling papillomavirus infection: a report of two cases. J Cutan Pathol 2015;42:652-656.
7 Choi JH, Shin DH, Shin DS, Cho KH: Subungual keratoacanthoma: ultrasound and magnetic resonance imaging findings. Skeletal Radiol 2007;36:769-772.

8 Levy DW, Bonakdarpour A, Putong PB, Mesgarzadeh M, Betz RR: Subungual keratoacanthoma. Skeletal Radiol 1985;13:287-290.

9 Sinha A, Marsh R, Langtry J: Spontaneous regression of subungual keratoacanthoma with reossification of underlying distal lytic phalynx. Clin Exp Dermatol 2005;30:20-22.

10 Keeney GL, Banks PM, Linscheid RL: Subungual keratoacanthoma. Report of a case and review of the literature. Arch Dermatol 1988; 124:1074-1076. 